\title{
EXPERIMENTAÇÃO ALIADA A RESOLUÇÃO DE PROBLEMAS NO ENSINO DE QUÍMICA: O QUE TEM SIDO DISCUTIDO?
}

\author{
EXPERIMENTATION ALLIED TO PROBLEM SOLVING IN CHEMISTRY \\ TEACHING: WHAT HAS BEEN DISCUSSED? \\ Claudia Smaniotto Barin ${ }^{1}$, Thanise Beque Ramos ${ }^{2}$ \\ Recebido: fevereiro/2020 Aprovado: outubro/2021
}

Resumo: A complexidade do Ensino de Química tem sido relatada na literatura, requerendo de professores novas práticas pedagógicas capazes de superar este desafio e engajar os alunos no processo de aprendizagem. Nesse sentido, a experimentação tem sido discutida como uma alternativa viável para despertar o interesse dos alunos pelo aprendizado. Assim, o trabalho visa avaliar o que tem sido discutido sobre as potencialidades e desafios do uso da Experimentação aliada a Resolução de Problemas para o Ensino de Química. Apoiados em uma pesquisa bibliográfica de caráter exploratório, analisou-se os artigos publicados no período de 2008 -2019 nas revistas Química Nova na Escola e Revista Electrônica de Enseñanza de las Ciências. As buscas resultaram em 194 artigos na Revista Química Nova na Escola, sendo que a análise destes resultou na seleção de apenas 8 trabalhos. Na Revista Electrónica Enseñanza de las Ciências, obteve-se aproximadamente 45 resultados, porém, só 2 abordavam a Resolução de Problemas aliada a Experimentação. Com base nessa pesquisa, pode-se inferir que a integração dessas metodologias ainda é pouco explorada no contexto do Ensino de Química, e chama a atenção que nenhum dos artigos avaliados aborda a Educação Profissional e Tecnológica.

Palavras-chave: Resolução de Problemas, Experimentação, Ensino de Química, EPT.

\begin{abstract}
The complexity of teaching Chemistry has been reported in the literature, requiring teachers new pedagogical practices capable of overcoming this challenge and engaging students in the learning process. In this sense, experimentation has been discussed as a viable alternative to arouse students' interest in learning. Thus, the work aims to evaluate what has been discussed about the potential and challenges of using Experimentation combined with Problem Solving for Teaching Chemistry. Based on an exploratory bibliographic research, the articles published in the period 2008-2019 in the journals Química Nova na Escola and Revista Electrónica de Enseñanza de las Ciências were analyzed. The searches resulted in 194 articles in Revista Química Nova na Escola, and their analysis resulted in the selection of only 8 works. In the Revista Electrónica Enseñanza de las Ciências, approximately 45 results were obtained, however, only 2 addressed Problem Solving combined with Experimentation. Of the articles evaluated, none addresses Vocational and Technological Education.
\end{abstract}

Keywords: Problem Solution, Experimentation, Chemistry Learning, VTE.

\section{Introdução}

A Química é uma Ciência abstrata e complexa, o que a torna, para muitos alunos, desinteressante, não apenas pela dificuldade de aprendizado, mas por não vislumbrarem sua

https://orcid.org/0000-0002-6549-5476 - Licenciada em Química e Mestre em Educação Profissional e Tecnológica pela UFSM., Santa Maria, RS - Brasil. Av. Roraima no 1000 - Cidade Universitária, Bairro Camobi, Santa Maria - RS, Brasil CEP: 97105-900. E-mail: thaniseramosqmc@gmail.com

https://orcid.org/0000-0003-3393-5526 - Doutora em Ciências pelo IQSC/USP. Professora Associada II do Departamento de Química da UFSM, Santa Maria, RS-Brasil. Av. Roraima no 1000 - Cidade Universitária, Bairro Camobi, Santa Maria - RS, Brasil CEP: 97105-900 -E-mail: claudiabarin@ufsm.br 
aplicabilidade no dia a dia. Isto pode estar associado as práticas pedagógicas empregadas no ensino de Química, comumente baseadas no método expositivo e desconectadas do cotidiano dos alunos, levando-os a questionar qual a real importância do estudo da Química para suas vidas (SILVA; DEL PINO, 2009). Nesse sentido, a experimentação, surge como uma alternativa viável para despertar o interesse dos alunos pelo aprendizado e tem sido explorada por mais de um século nas escolas, ainda que com pouca assiduidade (GALIAZZI; GONÇALVES, 2004). Segundo Giordan (1999), essa prática pedagógica tem um caráter motivador e lúdico, pois é vinculada aos sentidos, e desenvolve competências e habilidades científicas, bem como a formação de um espírito social colaborativo para a aprendizagem.

De Oliveira (2010), corrobora a visão de Giordan (1999) no que se refere a potencialidade motivadora e engajadora dos alunos, principalmente quanto ao trabalho em grupo e o desenvolvimento da iniciativa e tomada de decisão. De acordo com a autora, a experimentação estimula a criatividade, aprimora a capacidade de observação e o registro de informação, a análise dados e proposição das hipóteses para os fenômenos, além de propiciar a compreensão da natureza da ciência e o papel do cientista em uma investigação.

As atividades experimentais podem ser classificadas em 3 tipos: atividades de demonstração, de verificação e de investigação (De OLIVEIRA, 2010; VIEIRA et al., 2021), como pode ser observado na Figura 1.

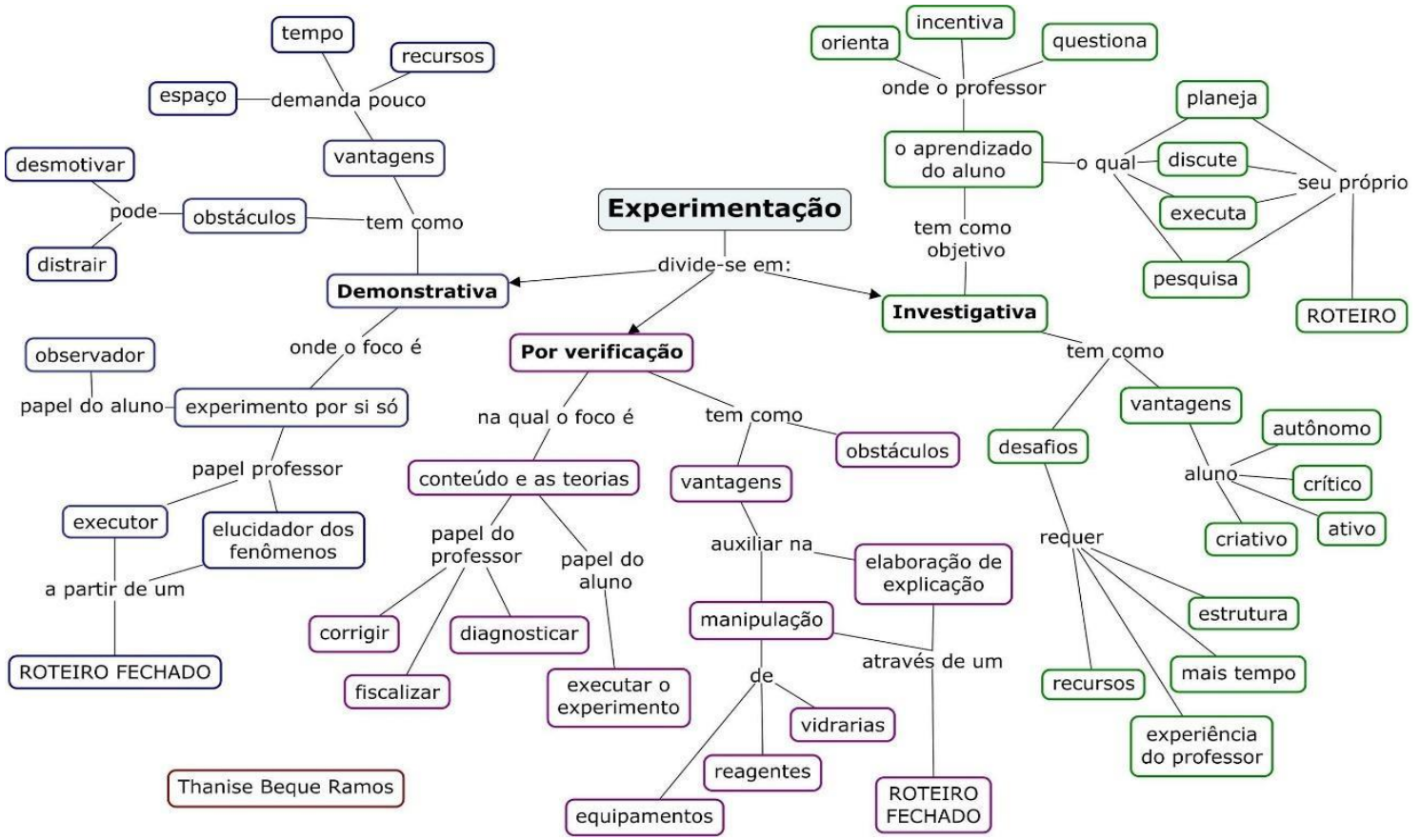

Figura 1 - Mapa conceitual sobre os tipos de experimentação. (Adaptado de De Oliveira (2010).

Nas atividades experimentais de demonstração o professor executa o experimento, e os alunos observam os fenômenos ocorridos, sendo comumente utilizadas por professores em escolas com poucos recursos materiais, estruturais e de tempo. Podem auxiliar no processo de aprendizagem, mesmo que não haja manipulação por parte dos alunos, desde que o professor "propicie oportunidades para que os alunos possam refletir sobre os fenômenos observados, formulem hipóteses, analisem variáveis que interfiram no experimento, discutam criticamente os conteúdos científicos que explicam os fenômenos" (DE OLIVEIRA, 2010, p. 148). 
As atividades experimentais de verificação vão além da mera demonstração e têm o objetivo de averiguar/confirmar alguma teoria, sendo os resultados comumente previsíveis e os conceitos previamente estudados pelos alunos. A visualização dos fenômenos, nesse caso, pode contribuir de alguma forma a aprendizagem, porém o professor deve estimular a relação entre a teoria e a prática, questionar e sugerir variações dentro das técnicas utilizadas, discutir os resultados obtidos para promover a discussão e a argumentação, buscando assim uma aprendizagem mais efetiva (DE OLIVEIRA, 2010).

As atividades investigativas, segundo De Oliveira (2010), vêm ganhando destaque nos recentes estudos sobre Experimentação, pois colocam o professor como mediador do processo e os alunos como protagonistas na construção do seu conhecimento, interpretando, investigando e propondo soluções para situações problemas de seu interesse. Na mesma linha de raciocínio, Suart e Marcondes (2008) apontam que ao planejar uma aula experimental de forma a incentivar a resolução de uma situação-problema, o professor está contribuindo para o desenvolvimento do senso crítico, por meio do raciocínio lógico e da argumentação para apresentação de uma solução plausível.

Nesse tipo de experimentação, a característica é da atividade aberta, na qual não se disponibiliza roteiros, e os problemas não possuem soluções imediatas, sem que haja raciocínio, formulação, reflexão e discussão. Ao contrário das atividades tradicionais de ensino, não precisa haver uma dependência direta com o cronograma e os conteúdos do currículo, nem aulas expositivas anteriores a experimentação, desta forma os resultados não são previsíveis e os conceitos são abordados conforme a experimentação vai sugerindo ou requerendo (DE OLIVEIRA, 2010).

As críticas às atividades de demonstração e verificação vêm crescendo ao longo das últimas décadas. Esse fato pode estar relacionado ao potencial propiciado pelas atividades investigativas, que supera as demonstrativas e de verificação. No entanto, apesar das críticas, Galiazzi e Gonçalves (2004), apontam que as atividades demonstrativas e de verificação são as mais comumente utilizadas no contexto de sala de aula, devido à praticidade de aplicação, que demanda menor esforço dos alunos e professor, bem como podem ser feitas em sala de aula.

[...] a visão que sobressai nos relatos é a da experimentação empirista do fazer para extrair a teoria, com uma abordagem tradicional do demonstrar para crer, contribuindo para a manter a hegemonia de uma visão de Ciência objetiva, neutra, apoiada nas teorias surgidas da observação (GALIAZZI; GONÇALVES, 2004, p. 326).

A experimentação investigativa é algumas vezes preterida pelo fato de demandar maior tempo de trabalho, preparo dos professores para se depararem com situações não previstas, estrutura e recursos materiais, o que muitas vezes dificulta sua proposição. Quanto ao desafio de estrutura e recursos, estes podem ser ultrapassados pelo uso de práticas com materiais alternativos e que podem ser desenvolvidas em ambiente aberto ou mesmo na sala de aula. Assim, o que realmente precisa mudar é a postura do professor, compreendendo a importância da experimentação investigativa, preparando-se para utilizá-la em suas aulas. Nesta perspectiva, Suart, Marcondes e Lamas (2010) complementam: 
[...] o professor, ao elaborar e executar essas atividades, precisa se preparar conceitualmente e pedagogicamente, porque podem acontecer situações não planejadas no decorrer da aula como, por exemplo, questionamentos não diretamente relacionados ao assunto em estudo, administração do tempo para a realização das atividades, resultados não condizentes com o esperado. Assim, precisa ter flexibilidade para mudar o caminho da aula, tomando o cuidado de não criar ainda mais dificuldades conceituais nos alunos (SUART; MARCONDES; LAMAS, 2010, p. 206).

Alguns professores, no entanto, não atentam para aspectos fundamentais da Experimentação como a "elaboração de uma hipótese, coleta e análise de dados, reflexão dos resultados à luz do aporte teórico e das hipóteses enunciadas" (SUART; MARCONDES, 2008, p. 2). Segundo os autores eles se preocupam mais com o produto que com o processo, coibindo o desenvolvimento cognitivo e a percepção da construção de ideias a partir dos fenômenos.

A experimentação investigativa é, portanto, a que contribui de forma mais efetiva para a construção do conhecimento, pois nela o aluno assume papel de protagonista do processo. No entanto, destaca-se que a experimentação investigativa, quando aliada à Resolução de Problemas torna-se ainda mais efetiva nesse processo de produção de saberes, pois como afirma Pozo (1998, p. 9), "ensinar os alunos a resolver problemas supõe dotá-los da capacidade de aprender a aprender".

\section{A Resolução de Problemas no Ensino de Química}

O ensino baseado na transmissão de conceitos é muito criticado por pesquisadores da área da educação, pois faz com que o estudante permaneça em uma atitude passiva, como mero ouvinte e receptor de informações, as quais nem sempre tem relação com seu cotidiano ou com seus conhecimentos prévios, pois fazem parte costumeiramente de livros didáticos que não levam em consideração o contexto social do estudante. Desta forma, Guimarães (2009, p. 198) propõe: "Porque não criar problemas reais e concretos para que os aprendizes possam ser atores da construção do próprio conhecimento?"

Schnetzler (2002) aponta que os últimos 20 anos de investigação sobre a didática das Ciências foram marcados por pesquisas em temas diversos, a fim de propor diferentes metodologias que apoiem a ruptura da transmissão do conhecimento, tais como a Resolução de Problemas; a Experimentação; os Materiais Didáticos Digitais; Abordagem Ciência, Tecnologia e Sociedade (CTS), entre outros.

Segundo Goi e Santos (2009), a Resolução de Problemas é uma proposta teóricometodológica que visa promover o aluno como sujeito ativo no processo de aprendizagem. Essa metodologia não é nova, pois ainda nos anos 90, Pozo, já destacava sua importância para Educação Básica, afirmando que o "verdadeiro objetivo final da aprendizagem baseada na solução de problemas é fazer com que o aluno adquira o hábito de propor-se problemas e de resolvê-los como forma de aprender" (POZO, 1998, p.15). Portanto, observa-se a relevância desta para o desenvolvimento integral dos alunos, que também é um dos objetivos da Educação Profissional e Tecnológica, pois o estudante passa a incorporar esse hábito tanto em sua vida 
pessoal quanto profissional, formando-se para ingressar no mundo do trabalho e apto para atuar em setores tecnológicos e científicos de forma crítica e emancipada.

Lopes (1994) também destaca algumas ideias sobre a importância da Resolução de Problemas no ensino das Ciências, dentre elas o aumento do conhecimento científico, dos conceitos, atitudes, técnicas e capacidades dos alunos; abrir novas portas para uma mudança de atitude tanto de alunos quanto de professores em sala de aula e também fora dela; o aproveitamento da potencialidade que os alunos têm por gostarem de experimentar desafios; a produção do saber e do saber-fazer; e por fim, o desenvolvimento de diversas habilidades científicas, sociais, de comunicação, e de atividades complexas, como o pensamento criativo e tomada de decisões. $O$ termo problema refere-se a uma questão em que uma pessoa não possui uma maneira rápida e mecânica para resolver, Costa e Moreira (1996) definem como

[...] um problema é um estado subjetivo da mente, pessoal para cada indivíduo, um desafio, uma situação não resolvida, cuja resposta não é imediata, que resulta em reflexão e uso de estratégias conceituais e procedimentais, provocando uma mudança nas estruturas mentais. (COSTA; MOREIRA, 1996, p. 177)

Nesta perspectiva, Pozo (1998, p. 16) argumenta que uma situação pode ser considerada um problema na medida em que não há um procedimento automático para solucioná-lo de maneira imediata, sem que haja um "processo de reflexão ou uma tomada de decisões sobre a sequência de passos a serem seguidos". Sendo assim, há diferenciação entre problema e exercício, pois pode haver equívocos sobre os conceitos da aplicação da Resolução de Problemas como sua associação às listas de exercícios comumente utilizadas no Ensino das Ciências Exatas. O exercício baseia-se no uso de habilidades e técnicas já conhecidas para situações habituais em que já se conhece a prática ou o caminho para resolvê-lo, é aplicado em rotinas automatizadas em que não há nada de novo e consolidam-se habilidades instrumentais práticas (POZO, 1998).

A distinção entre a Resolução de Problemas e os exercícios depende ainda do contexto em que se encontra o aluno (POZO, 1998), por exemplo, enquanto para alguns, a utilização da Cromatografia para análise de compostos presentes em uma dada solução, pode ser uma técnica habitual, um simples exercício do seu ofício, para outros pode se apresentar como um problema, requerendo conhecimentos, estratégias e tomada de decisões para solucioná-lo.

Desta forma, conhecido o contexto em que se aplica tal situação, a Resolução de Problemas proporciona o desenvolvimento de diversas habilidades nos alunos, pois situações abertas os levam a utilizar-se dos conhecimentos prévios, buscar conhecimentos novos, levantar hipóteses e estratégias para resolvê-las, assim o desenvolvimento dos alunos vai além, segundo Pozo (1998, p.14), cria "neles o hábito e a atitude de enfrentar a aprendizagem como um problema para o qual deve ser encontrada uma resposta". Assim, os alunos terão a compreensão de que sua aprendizagem depende de seu engajamento em buscar o conhecimento, em questionar-se, e não apenas esperar pelas respostas prontas vindas do professor ou dos seus livros didáticos (POZO, 1998). Os problemas podem ser classificados de diferentes formas (Figura 2): 


\section{Dedut io ou indut io}

depende do raciocínio que o sujeito precisa realizar

Bem def nido ou mal def nido

bem def nido é possível ident f ćar houve solução, enquanto o mal def nido é aquele onde o ponto de part da ou as normas que est pulam quais são os passos necessários para resolver a tarefa são pouco claros, conduzindo a diferentes interpretações e soluções.

\section{Cient $f$ co}

onde a solução apoia-se no método cient $f$ ćo, na realização de experiências planejadas para $f$ in de validação das hipóteses, por meio de medições precisas, condições ideais e confronto das hipóteses a part $\dot{r}$ dos resultados obt dos

\section{Cot dianos}

têm por objet ìo a ef ciência/sucesso na resolução. Surgem de questões cot dianas e não propõem a ref exão sobre os resultados

Escolares qualitat ios

os alunos resolvem teoricamente, sem ter de recorrer a experimentos prát cos ou cálculos numéricos. Possibilita que o estudante aprofunde seus conhecimentos sobre determinados conceitos, seja consciente de suas ideias e discuta com seus colegas.

Escolares quant tat ios

os alunos devem resolver cálculos e manipular dados numéricos para chegar a uma solução numérica ou não. Podem ajudar na aplicação dos conhecimentos, técnicas e habilidades matemát cas, porém podem virar mero exercício se não for bem planejado.

Pequenas pesquisas

os alunos devem buscar uma solução prát ca e "Implicam uma aprendizagem de habilidades e estratégias, assim como de conceitos, adotando também algumas das característ cas dos outros dois t pos de problemas descritos: a busca de uma conexão entre os conhecimentos prévios e os fenômenos a serem estudados e a necessidade, em muitos casos, de medir e submeter essas medidas a cálculos quant tat vos como instrumento para inferir leis ou comprovar hipóteses" (POZO, 1998, p. 82).

Figura 2 - Classificação dos problemas quanto ao tipo. Adaptado de Pozo (1998).

Pequenas pesquisas introduzidas nas aulas como forma de aproximar os alunos de um trabalho científico, são propostas por Pozo (1998), pois segundo o autor, além de desenvolver comportamentos como reflexão, questionamentos, estratégias de busca, sistematização e análise de dados, elas propiciam a "compreensão e a interação com o mundo que os cerca" (POZO, 1998, p. 83). Também se destaca que não basta levar os alunos ao laboratório, proporIhes o problema e disponibilizar todas as instruções e roteiros de como solucioná-lo, nem tampouco realizar um experimento demonstrativo, ilustrando uma lei ou conceito, nessas situações, o autor enfatiza que não há um problema real a ser resolvido.

Pozo (1998) complementa afirmando que problemas abertos confrontam o aluno com algo diferente do conhecido, pois ele precisa interpretá-los e buscar o conhecimento para solucionar esse tipo de problema, bem como traçar planos, hipóteses, testá-las e desenvolver a capacidade crítica para julgá-las. $\mathrm{O}$ autor salienta que os problemas fechados propõem todas as instruções e as informações para solucioná-los, o que pode fazer com que o aluno não o encare como problema e sim como um simples exercício.

O autor propõe ainda o problema semiaberto, o qual promove um equilíbrio entre os outros dois tipos de problema, pois neste

[...] contém informação que restringe os possíveis cenários nos quais é possível definir o problema, auxiliando o aluno a concentrar-se na tarefa prevista, mas confrontando-o, ainda, com uma tarefa aberta e não como um simples exercício (Pozo, 1998, p. 87). Assim, 
no problema semiaberto, são oferecidas algumas informações para nortear o estudante em sua pesquisa, porém ele ainda precisa sistematizar a forma de solucionar esse problema.

Lopes (1994), faz uma relação da Resolução de Problemas aliada à Experimentação, criticando a experimentação utilizada como mera ilustração de conceitos, pois ela tem um papel mais nobre, não só de permitir aos alunos experimentarem mas de permitir o desenvolvimento dos conceitos e processos. Por isso, o autor propõe que a experimentação seja encarada como uma Resolução de Problemas, onde o estudante formula hipóteses, planeja experimentos para verificar as hipóteses, executa o experimento, registra, recolhe e interpreta dados, tira conclusões e avalia os resultados e métodos utilizados.

Portanto, percebe-se que a metodologia de Resolução de Problemas pode ser excelente aposta para o Ensino de Química na Educação Profissional e Tecnológica, pois pode desenvolver nos alunos a concepção de que os problemas encontrados no mundo do trabalho e no seu dia a dia podem ser solucionados através da pesquisa e da busca pelo conhecimento. A Resolução de Problemas não pretende minimizar a aprendizagem dos conceitos químicos e das Ciências Exatas, nem os deixar em segundo plano, mas relacioná-los diretamente com a realidade, preparando os alunos para se posicionarem frente as situações adversas que o trabalhador pode encontrar na sua profissão.

O professor também é sujeito nesse processo, pois é a partir de suas análises e reflexões que se tem o ponto de partida do processo, além disso, vai desenvolver sua formação e seus saberes, pois ele pode sentir-se desafiado com as propostas dos alunos, e deparar-se também com situações que não são presenciadas em aulas tradicionais e rotineiras.

$\mathrm{Na}$ busca pelas soluções dos problemas, os alunos são estimulados a refletir sobre sua aprendizagem e suas concepções, socializar suas opiniões, a discutir ideias novas, debater proposições, tornando o processo democrático, e preparando-os para as situações cotidianas em que os indivíduos são constantemente desafiados a defenderem suas posições, identidades e respeitar as opiniões e as subjetividades dos outros. Quando os alunos aplicam as hipóteses geradas, podem chegar ou não à resolução dos problemas, porém todas as tentativas são válidas, proposições dos porquês que ocorreram as falhas geram dúvidas, e, por fim, promove o conhecimento, o valor está no caminho percorrido, na reação do aluno ao buscar as soluções.

Com base na conceituação dos tipos de experimentação e da resolução de problemas, busca-se por meio deste artigo investigar se estas metodologias têm sido abordadas de forma consorciada, potencializando a construção do conhecimento químico.

\section{Metodologia}

O trabalho consiste de uma pesquisa bibliográfica de caráter exploratório. Desta forma, designou-se como fonte de dados os trabalhos publicados na Revista Química Nova na Escola, uma das mais utilizadas no âmbito do Ensino de Química, e a Revista Electrónica Enseñanza de las Ciências, devido sua relevância no Ensino de Ciências. Os resultados foram filtrados a partir de 2008, a fim de verificar o que tem sido publicado sobre o assunto na última década.

Para busca utilizou-se as palavras-chaves: "Experimentação e Resolução de Problemas". Utilizou-se como critérios de inclusão que as palavras-chaves utilizadas estivessem no título, ou 
resumo, ou palavras-chaves, ou ainda no artigo completo, dentro do espaço temporal de 2008 a 2018, sendo descartados os trabalhos que não atendiam aos critérios de inclusão. Os resultados decorrentes da busca são apresentados a seguir.

\section{Desenvolvimento}

A busca na Revista Química Nova na Escola resultou em 194 resultados, porém seguindo os critérios de inclusão utilizados, apenas 8 trabalhos foram selecionados. Na Revista Electrónica Enseñanza de las Ciências (REEC), obteve-se 45 resultados, porém, somente 2 continham as palavras Resolução de Problemas e Experimentação. Os trabalhos selecionados (10) podem ser visualizados no Quadro 2, bem como o tipo de problema abordado e logo a seguir apresenta-se uma descrição detalhada de cada um desses artigos, de forma a desenhar o estado da Arte da Experimentação aliada à Resolução de Problemas, no contexto do Ensino de Química.

Quadro 2: Classificação dos artigos encontrados nas Revistas QNESC e REEC

\begin{tabular}{|c|c|}
\hline \multicolumn{2}{|l|}{ Química Nova na Escola } \\
\hline Artigo & Classificação \\
\hline $\begin{array}{l}\text { SILVA, Daniela Rodrigues da; DEL PINO, José Cláudio, 2009. Um Estudo do } \\
\text { Processo Digestivo como Estratégia para Construção de Conceitos } \\
\text { Fundamentais em Ciências. }\end{array}$ & $\begin{array}{l}\text { Problema } \\
\text { semiaberto. }\end{array}$ \\
\hline $\begin{array}{l}\text { GOI, Mara Elisângela Jappe; SANTOS, Flávia Maria Teixeira dos, } 2009 . \\
\text { Reações de Combustão e Impacto Ambiental por meio de Resolução de } \\
\text { Problemas e Atividades Experimentais. }\end{array}$ & $\begin{array}{l}\text { Problema } \\
\text { Semiaberto. }\end{array}$ \\
\hline $\begin{array}{l}\text { SUART, Rita de Cassia; MARCONDES, Maria Eunice Ribeiro; LAMAS, Maria } \\
\text { Fernanda Penteado, 2010. A Estratégia "Laboratório Aberto" para a } \\
\text { Construção do Conceito de Temperatura de Ebulição e a Manifestação de } \\
\text { Habilidades Cognitivas. }\end{array}$ & $\begin{array}{l}\text { Problema } \\
\text { Semiaberto. }\end{array}$ \\
\hline $\begin{array}{l}\text { De SOUZA, Fabio Luiz; MARTINS, Patrícia, 2011. Ciência e Tecnologia na } \\
\text { Escola: Desenvolvendo Cidadania por meio do Projeto "Biogás - Energia } \\
\text { Renovável para o Futuro" }\end{array}$ & $\begin{array}{l}\text { Problemas } \\
\text { fechado e } \\
\text { semiaberto. }\end{array}$ \\
\hline $\begin{array}{l}\text { FERREIRA, Luiz Henrique; HARTWIG, Dácio Rodney; OLIVEIRA, Ricardo } \\
\text { Castro de. Ensino Experimental de Química: Uma Abordagem Investigativa } \\
\text { Contextualizada }\end{array}$ & $\begin{array}{l}\text { Problema } \\
\text { Semiaberto. }\end{array}$ \\
\hline $\begin{array}{l}\text { De SOUZA, Paulo Vitor Teodoro; SILVA, Douglas; AMAURO, Quintino; MORI, } \\
\text { Rafael Cava; MOREIRA, Patrícia Flavia da Silva Dias, 2015. Densidade: Uma } \\
\text { Proposta de Aula Investigativa }\end{array}$ & $\begin{array}{l}\text { Problema } \\
\text { Fechado. }\end{array}$ \\
\hline $\begin{array}{l}\text { CRUZ, Antônio A.C.; RIBEIRO, Vanessa. G.P..; LONGHINOTTI, Elisane; } \\
\text { MAZZETTO, Selma E., 2016. A Ciência Forense no Ensino de Química por } \\
\text { Meio da Experimentação Investigativa e Lúdica }\end{array}$ & $\begin{array}{l}\text { Problema } \\
\text { Fechado. }\end{array}$ \\
\hline $\begin{array}{l}\text { SOUZA, Cleuzane R, SILVA. Fernando C. 2018. Uma Sequência Investigativa } \\
\text { Relacionada à Discussão do Conceito de Ácido e Base }\end{array}$ & $\begin{array}{l}\text { Problema } \\
\text { Semiaberto. }\end{array}$ \\
\hline
\end{tabular}


REEC. Revista Electrónica Enseñanza de las Ciências

\begin{tabular}{|l|c|}
\hline \multicolumn{1}{|c|}{ Artigo } & Classificação \\
\hline $\begin{array}{l}\text { ZAPPE, Janessa Aline; BRAIBANTE, Mara Elisa Fortes, 2015. Contribuições } \\
\text { através da temática agrotóxicos para a aprendizagem de química e para a } \\
\text { formação do estudante como cidadão. }\end{array}$ & ---- \\
\hline $\begin{array}{l}\text { Kasseboehmer, A. C, Ferreira, L. H, 2013. O método investigativo em aulas } \\
\text { teóricas de Química: estudo das condições da formação do espírito } \\
\text { científico }\end{array}$ & $\begin{array}{c}\text { Aberto, } \\
\text { semiaberto } \\
\text { e fechado. }\end{array}$ \\
\hline
\end{tabular}

Fonte: Autora

Silva e Del Pino (2009), discutem sobre a importância da participação do aluno no processo de aprendizagem, citando Echeverria e Pozo (1994), como pressupostos teóricos que ancoram a potencialidade da Resolução de Problemas como uma metodologia diferenciada que envolve os sujeitos ativamente na construção dos seus saberes. A pesquisa apoia-se em um Estudo de Caso para alunos das séries finais do Ensino Fundamental, na disciplina de Ciências. Os autores apontam as dificuldades dos alunos em construírem hipóteses para solução dos problemas no início das atividades, em decorrência de estarem acostumados com o ensino tradicional, ou seja, que não tira o aluno da passividade. Os autores salientam ainda a importância do papel do professor como mediador durante as atividades, incentivando o desenvolvimento de atividades em que todos os sujeitos pertencentes ao grupo podem participar ativamente.

De acordo com Silva e Del Pino (2009), após a superação das dificuldades iniciais a turma foi interagindo mais e as discussões foram baseadas nas questões que começaram a aparecer durante as aulas, indicando que é possível trabalhar conteúdos mais complexos e abstratos com os alunos da educação básica, desde que sejam contextualizados e significativos para eles. Para os autores, é desafiador trabalhar com resolução de problemas em um contexto tradicional onde os alunos são acostumados desde o início a copiarem respostas prontas de livros, e é um processo demorado até que se desacomodem, no entanto com persistência esses desafios são ultrapassados, e os alunos passam a ter uma postura mais ativa nas aulas levando sempre questionamentos do seu cotidiano para sala de aula.

Goi e Santos (2009) discutem em seu artigo que a experimentação foi proposta nos currículos escolares das Ciências da Natureza há mais de 30 anos, porém foi trabalhada de forma que não desenvolveu o espírito científico nos alunos como se esperava, pois resultou apenas em cumprimento de roteiros e "mera manipulação" de reagentes e vidrarias. Para superar essa forma de abordagem da experimentação, as autoras propuseram um estudo experimental, aplicado por um período de quatro semanas a um grupo de 37 alunos de duas turmas do Ensino Médio de uma escola de Porto Alegre (RS). A seguir descrevemos um pouco da abordagem das autoras.

De acordo com Goi e Santos (2009), após uma breve discussão sobre a temática "Reações de combustão e impacto ambiental" os problemas foram apresentados aos grupos para que fossem solucionados. Primeiro os estudantes tinham de propor hipóteses e por fim testá-las, discutindo os resultados. Os problemas eram do tipo semiabertos, pois são fornecidos os 
princípios gerais para a resolução dos mesmos. No último problema os alunos tinham que propor alternativas teórico-práticas para amenizar o impacto ambiental que os combustíveis causam na natureza. As autoras relatam o desenvolvimento da autonomia, sendo a atividade uma excelente estratégia para desenvolver as potencialidades criativas dos alunos, mobilizando conhecimentos e habilidades destes por meio de um trabalho teórico e prático".

A temática "experimentação como forma de aprimoramento da aprendizagem em química é discutida no artigo de Suart, Marcondes e Lamas (2010). As autoras enfatizam que da forma que tem sido implementada no ensino, a experimentação não tem proporcionado aos alunos o desenvolvimento das "habilidades essenciais para o exercício da cidadania", nem a construção de conceitos químicos, pois as atividades são apenas de verificação de conceitos não tendo relação da teoria com a prática. Nesse sentido, as autoras destacam a importância das atividades investigativas, que levam uma situação problema aos alunos e, os instiga a propor hipóteses, analisar dados, além de promover a participação ativa na construção do conhecimento, explorando dessa forma suas habilidades cognitivas. Portanto, a experimentação deve instigar o aluno e não dar soluções prontas.

É neste contexto que Suart, Marcondes e Lamas (2010), propõem uma experimentação sobre o conceito de temperatura de ebulição para alunos do Ensino Médio de uma escola pública da cidade de São Paulo. Os alunos foram questionados sobre "quais fatores afetam a temperatura de ebulição de um material?" Depois de proporem as hipóteses, eles testaram seus experimentos, e por fim, discutiram os resultados entre os grupos e produziram um relatório. Foi observado pelas autoras que os alunos tiveram dificuldades em propor objetivos e fazer suas previsões para os experimentos, pois estavam acostumados com receitas prontas. Alguns omitiram suas hipóteses, enquanto outros se preocuparam com o controle de variáveis, não demonstrando dificuldades para a realização dos experimentos, mas na análise de dados e na expressão escrita, além do fato que nem todos se engajaram igualmente na proposta. Assim, as autoras apontam que o professor precisa estar preparado conceitual e pedagogicamente ao planejar e executar esse tipo de atividade, pois podem acontecer questionamentos não relacionados com o assunto da aula, o tempo pode não ser bem administrado, e os resultados não serem os esperados.

De Souza e Martins (2011), em seu artigo denominado "Ciência e Tecnologia: Desenvolvendo cidadania por meio do Projeto Biogás - Energia Renovável para o futuro", tratam da importância da relação de conteúdos com a interface CTS (Ciência, Tecnologia e Sociedade). A proposta consiste de uma atividade experimental investigativa, na qual os alunos formularam hipóteses para a solução de um problema, que era intitulado: "Fontes alternativas de energia". Inicialmente os alunos pesquisaram sobre o Biogás como fonte de energia alternativa, e propuseram como construir um biodigestor simples. Os autores relatam que durante o processo os alunos realizaram outros experimentos sobre $\mathrm{pH}$, velocidade de reações e outras variáveis do Biodigestor.

Segundo os autores, os alunos foram acompanhando o processo durante semanas, controlando variáveis, observando, coletando dados, propondo conclusões. Nesse aspecto, os mesmos evidenciam a importância da participação em todas as etapas do processo, desde as coletas de dados até a resolução do problema, elaboração das conclusões e a comunicação dos 
resultados, fazendo com que eles tenham mais interesse e responsabilidade, além de desenvolverem diferentes habilidades (DE SOUZA; MARTINS, 2011).

Ferreira; Hartwig e Oliveira (2010), ressaltam em seu trabalho, que a experimentação seguida a partir de um roteiro procedimental dificilmente induz ao raciocínio e questionamento. Por isso, propuseram o ensino baseado em investigação para 58 alunos do 10 Ano do Ensino Médio, tendo como objetivo a determinação do teor de álcool na gasolina. Primeiramente, foi discutido com os alunos conceitos de solubilidade, miscibilidade e polaridade. Após discutiu-se sobre a gasolina, e então expôs-se a situação-problema, com o cuidado de não induzir na formulação de hipóteses. Desta forma, os alunos propuseram as soluções de acordo com o aporte teórico que vinham trabalhando ao longo do processo.

O objetivo principal do trabalho era averiguar como e, em que extensão, os alunos conseguem propor um procedimento experimental para a resolução de uma situação-problema. Os autores concluíram que apesar de observarem a dificuldade na redação dos relatórios pelos alunos, houve uma sequência lógica de raciocínio para a obtenção dos dados experimentais, e "o relatório propiciou a explicitação das concepções dos alunos, o que não ocorre quando um roteiro experimental é previamente fornecido" (FERREIRA; HARTWIG; OLIVEIRA, 2010, p. 105). Além disso, observaram que na ausência de um roteiro os alunos mostraram capacidade de utilizar conceitos e procedimentos para resolução do problema, aproximando a atividade realizada da atividade científica em que um pesquisador não possui um roteiro previamente fornecido.

De Souza et al. (2015), discutiram em seu artigo sobre a importância da Experimentação no Ensino de Química, segundo os autores, "são ferramentas que atuam como recursos pedagógicos na construção de conhecimentos, capacidades e habilidades" (p. 1), além disso, ressaltam as atividades experimentais investigativas pois propiciam a reflexão, discussão, ponderação, indo além da compreensão somente dos conceitos. Os autores também abordam a relevância da compreensão do conceito de densidade para o domínio da química, pois apesar de parecer um conceito fácil, alguns alunos têm dificuldade em sua aprendizagem. Desta forma, basearem-se na pedagogia problematizadora de Paulo Freire, na qual se entende a educação como prática social que proporciona a instrumentalização do educando (oprimido) para mudança de sua realidade social.

O estudo foi realizado em duas turmas de educação de jovens e adultos (EJA) da Escola Estadual Frei Egídio Parisí na cidade de Uberlândia (MG), em duas aulas de 50 minutos, conduzidas em três etapas descritas a seguir. No total, 36 alunos participaram do estudo. Para a aplicação da pesquisa, os autores usaram os três momentos de Delizoicov (1983) na qual a problematização inicial consistiu na apresentação de um texto com uma situação fictícia na qual os alunos deveriam tomar uma posição segundo a sua interpretação do caso, no segundo momento, a organização do conhecimento, os alunos "seguiram" um roteiro para estabelecer experimentalmente a densidade da água e de um objeto. Por fim, na aplicação do conhecimento, os alunos deveriam analisar os dados obtidos para resolver o caso. As considerações expostas pelos autores relatam o grande envolvimento dos alunos durante a atividade, com discussões sobre o caso em questão, diálogos sobre a bioética, propiciando conhecimentos pertinentes à ciência e à vida (DE SOUZA et al., 2015). 
Cruz et al. (2016), evidenciaram em seu artigo que o interesse pela ciência forense tem crescido nos últimos anos, principalmente entre os adolescentes, que tem acompanhado séries televisivas sobre o tema. Os autores abordam no artigo algumas técnicas forenses que pode ser utilizadas para abordar conceitos químicos de forma interdisciplinar, como a identificação das impressões digitais e de DNA, bem como a presença de sangue. Segundo os autores a experimentação "permite que os alunos visualizem, de maneira prática, a teoria explicada em sala de aula" (p. 168). A implementação da pesquisa dos autores se deu em três turmas regulares do último ano do Ensino Fundamental de um colégio da rede privada de Fortaleza, totalizando 120 alunos. O trabalho consistiu em etapas, sendo a primeira uma aula expositiva sobre as técnicas forenses e a relação com a química. Logo após foi apresentado uma história fictícia em que os alunos deveriam desvendar o crime através da experimentação

Cruz et al. (2016) observaram que a atividade aguçou a curiosidade dos alunos e gerou grande expectativa. Os discentes tornaram-se investigadores e protagonistas de sua aprendizagem. Os resultados relatados pelos autores apontam que a atividade proporcionou uma interação significativa e "o desenvolvimento de uma visão crítica do mundo que os cerca, tornando os conteúdos de Química menos abstratos e mais relevantes" (p. 171).

Souza e Silva (2018), afirmam que a forma como são abordados os conceitos ácido-base podem dificultar o entendimento destes pelos alunos, e propõem a abordagem "ENCl", Ensino de Ciências por Investigação aliado a experimentação, como uma alternativa viável para ensinar este conteúdo. Os autores citam Lamba (2015) e Marcondes (2009) como críticos de atividades experimentais que só verificam conceitos, e evidenciam que no $\mathrm{ENCl}$ as atividades experimentais assumem função mais ampla, pois a abordagem investigativa é privilegiada, proporcionando aos alunos a oportunidade de errarem durante o procedimento, a suposição de hipóteses e análise de dados, sem prejuízos ao aprendizado.

Apoiados em Hofstein, Kipnis e Abrahams (2013) para abordagem sócio construtivista do Ensino de Ciências, Souza e Silva (2018) propõem uma sequência didática organizada em 5 aulas: Na primeira houve a problematização inicial para conhecer as ideias prévias dos alunos, na qual, resumidamente, perguntava como poderiam organizar materiais de limpeza, alimentos, medicamentos e cosméticos em prateleiras de acordo com a sua afinidade química. Na segunda aula, os alunos debateram suas hipóteses para solução do problema, bem como experimentos para testá-las. Na terceira aula, os alunos discutiram os experimentos propostos e escolheram o que mais era viável para solucionar o problema. Na quarta aula, foram discutidos textos sobre indicadores ácido-base para sistematização dos conhecimentos aplicados no experimento. Por fim, na última aula, os alunos foram levados a escrever um texto sobre o problema em questão, assim como a questão ambiental por detrás do problema.

Os autores fizeram uma análise textual discursiva dos dados e perceberam que alguns alunos tiveram dificuldade nas atividades propostas, pois o $\mathrm{ENCl}$ exige uma postura mais ativa deles, e eles não são acostumados com atividades desse tipo. Também se evidenciou uma evolução na riqueza de detalhes escritas por eles que não havia antes. Ressaltou-se que apesar de alguns continuarem a ter concepções erradas sobre o assunto, as aulas foram marcadas por discussões, debates, diálogos e reflexões, envolvendo os alunos de forma ativa na aula. 
No primeiro artigo da Revista Electrónica Enseñanza de las Ciências (REEC), intitulado "Contribuições através da temática agrotóxicos para a aprendizagem de química e para a formação do estudante como cidadão", Zappe e Braibante (2015) discutem sobre a importância de um Ensino de Química contextualizado com a vivência dos alunos, e nesta perspectiva propõem a utilização de oficinas temáticas para engajar os alunos de forma ativa na construção do seu conhecimento, e para sua formação cidadã. Quanto às oficinas temáticas, as autoras apoiam-se em Marcondes (2008), que as caracteriza como a utilização do cotidiano dos alunos para organizar e promover a aprendizagem, abordando a Química a partir de temas relevantes e contextualizados com outros campos do saber. As autoras evidenciam a experimentação de caráter investigativo como forma de despertar o interesse e a curiosidade dos alunos.

As oficinas 2 e 4, propostas por Zappe e Braibante (2015), tinham caráter experimental, sendo os alunos conduzidos a um experimento investigativo na Oficina 2, para identificar grupos funcionais em agrotóxicos de baixa toxicidade, enquanto que na quarta oficina, os alunos investigaram o caráter ácido ou básico de alguns agrotóxicos. As autoras, no entanto, informam que ambas oficinas eram amparadas por roteiros. Assim, embora o artigo aborde em seu arcabouço a resolução de problemas, o fornecimento de roteiros para experimentação contradiz a proposição de uma experimentação apoiada na resolução de problemas, onde os alunos devem buscar a solução, como afirmam Pozo (1998) e De Oliveira (2010). Nesse sentido, pode-se inferir que a experimentação nesse caso é problematizada, mas não configura uma proposta de resolução de problemas, contradizendo o que afirmam as autoras quanto a essa competência "os alunos precisaram ter uma atitude investigativa, cooperativa e autônoma" (ZAPPE; BRAIBANTE, 2015, p.404).

Neste contexto, o trabalho das autoras tem um foco mais contundente na problematização e contextualização dos conceitos, pois como as mesmas afirmam, houve a valorização da aprendizagem Química, pois a contextualização com os agrotóxicos permitiu aos alunos perceberem a importância de aprender química: "A partir do momento em que os alunos conseguiram dotar de significado o que foi estudado em Química, percebe-se uma considerável evolução conceitual" (ZAPPE; BRAIBANTE, 2015, p. 404).

No segundo artigo da REEC, Kasseboehmer e Ferreira (2013) introduzem a pesquisa discutindo sobre o atual Ensino de Química nas escolas, o qual consideram cartesiano, desconectado e sem sentido para os alunos. Esse tipo de ensino, segundo os autores origina-se dos tempos antigos, de uma ciência filosófica. Os autores apoiam-se em Bachelard (1996), para afirmar que o ensino científico não deve se apoiar apenas em conceitos absolutos e sim na problematização, despertando o interesse do espírito científico.

Para Kasseboehmer e Ferreira (2013) o método investigativo vem se destacando na literatura, pois defende a participação ativa do estudante na construção do seu conhecimento e do espírito científico, numa perspectiva construtivista. No viés investigativo, não são fornecidos roteiros experimentais, mas lançados problema para que os estudantes elaborem hipóteses que devem ser testadas e comprovadas, desenvolvendo habilidades nos alunos como "espírito de cooperação, reflexão crítica, automotivação e responsabilidade" (p. 151), o que não é observado quando um roteiro experimental é seguido. 
A pesquisa de Kasseboehmer e Ferreira (2013) consistiu em onze atividades de investigação, aplicadas em duas escolas públicas e uma particular, envolvendo conceitos de transformação química, difusão gasosa, pressão e temperatura. As investigações podem ser classificadas em dois tipos: o primeiro enquadra problematizações para a compreensão de fenômenos, caso em que se solicitava ao estudante que, inicialmente, elaborasse uma explicação para a ocorrência daquele fenômeno, utilizando conceitos científicos. O outro tipo de investigação remete ao estudo de processos químicos elaborados pelo homem os quais, portanto, permitem mais de uma estratégia de resolução.

A implementação da aplicação dos problemas nas escolas se deu após o ensino, dos conceitos necessários a cada investigação. Assim, o professor lançava a atividade investigativa aos alunos, que deveriam trazer suas sugestões de hipóteses. As autoras apontam que tanto nas escolas públicas, quanto na particular os alunos apresentaram dificuldades em assimilar a necessidade de uma postura mais ativa. As autoras ainda relatam que embora apresentassem dificuldades em elaborar hipóteses, os alunos da escola particular apresentaram maior índice de acerto quanto aos conceitos abordados (KASSEBOEHMER; FERREIRA, 2013, p. 159). Neste sentido, as mesmas concluíram que as atividades de investigação impactaram de formas diferentes as duas escolas, e em questão da validação das hipóteses e da discussão coletiva pôde-se trabalhar a importância de não se aceitar tudo rapidamente, sem um questionamento prévio. Além disso, ressaltaram três fatores que contribuíram para o desenvolvimento do espírito científico: o conhecimento da natureza das ciências, que acontece quando há discussão e elaboração de hipóteses, o domínio de conceitos científicos e a disposição para a imersão em problemas científicos, ou seja, a motivação para a aprendizagem.

Os trabalhos acima descritos possibilitam a reflexão da potencialidade da experimentação, quando conduzida numa perspectiva de metodologia ativa, engajando os estudantes na construção do conhecimento e não apenas reproduzindo roteiros, pode contribuir para a formação de sujeitos críticos e reflexivos, características essas tão requeridas na maioria dos Projetos Pedagógicos de Curso e imprescindíveis para a formação de sujeitos autônomos. Nesse sentido, é preciso não apenas mudar a forma de abordagem da experimentação, é necessário que o professor modifique sua performance, tornando-se não mais o que transmite a informação, mas o que media e incentiva o processo de construção da aprendizagem.

Ademais, o professor ao adotar essa proposta metodológica onde o estudante constrói suas próprias hipóteses e caminhos para a solução de problemas, precisa estar ciente de seu papel de mediador da aprendizagem, mas além disso, estar aberto aos desafios que esta prática apresenta. Ao propor esta estratégia metodológica, o professor poderá defrontar-se com situações não planejadas, com questionamentos que podem ir além dos conceitos abordados em aula e precisa estar preparado para solucionar estas demandas, acompanhado dos estudantes.

Da mesma forma que é necessário uma mudança de postura dos professores para trabalhar numa perspectiva de experimentação investigativa ou de resolução de problemas vinculadas ou não à experimentação, os estudantes precisam tornar-se sujeitos ativos do processo. Essa necessidade de sair do papel de receptor e passar a construir seu aprendizado 
apoiado pelo professor, nem sempre é aceita pelos estudantes, que preferem a postura passiva a qual estão acostumados.

Considerando o que apontam Echeverría e Pozo (1994, p. 19):

[...]quando um aluno ou qualquer pessoa enfrenta uma tarefa do tipo que denominamos problema, precisa colocar em ação uma ampla série de habilidades e conhecimentos. Essas habilidades e conhecimentos podem variar e, de fato, variam de acordo com o tipo de problema com o qual se deparam.

Desta forma, esse desafio de mobilizar habilidades e conhecimentos precisa ser trabalhado com os estudantes e superado para que possam assim engajar-se e tornarem-se autores de sua própria aprendizagem. Nesse sentido, o professor deve iniciar a proposição de problemas de forma gradual, iniciando com problemas mais simples e ir aos poucos ampliando a complexidade, de forma a dar tempo para os estudantes se adaptarem com a proposta metodológica.

Este desafio é corroborado por Silva e Del pino (2009), que afirmam que os estudantes estão habituados a uma abordagem tradicional e que o processo de ruptura dessa passividade, demanda persistência do professor. Mas, como apontam os autores, uma vez que se desacomodem os estudantes se tornam mais participativos e engajados na aprendizagem, trazendo para sala de aula, questionamentos do seu cotidiano, pois como afirmam Hofstein, Kipnis e Abrahams (2013), os estudantes precisam de oportunidades para expressar o que pensam e colocar em prática, suas ideias sobre as ciências e como esta se relaciona com seu dia a dia.

Por fim, observa-se ao analisar os artigos, que em nenhum deles a Educação Profissional e Tecnológica (EPT) foi mencionada, evidenciando uma demanda de pesquisa acerca dessa modalidade de ensino, onde a experimentação imbricada com resolução de problemas, pode ter uma contribuição importante para formação dos aprendizes para o Mundo do Trabalho.

\section{Considerações Finais}

Com base nos dados retornantes da pesquisa realizada, pode-se afirmar que a abordagem da Resolução de Problemas aliada a Experimentação ainda é limitada no que se refere ao Ensino de Química, mas que podem ser uma excelente alternativa para superar as dificuldades de aprendizado, engajando os estudantes na construção do conhecimento.

Esse híbrido metodológico requer, no entanto, uma ruptura de paradigmas, onde o ensino passa a ser centrado no estudante e não mais no conteúdo, propiciando o desenvolvimento da criatividade e a formação de um cidadão capaz de analisar de forma crítica os problemas encontrados no seu cotidiano. Ademais a integração dessas metodologias de ensino potencializa a construção de saberes na coletividade, o que pode contribuir para uma melhoria das relações em sala de aula, considerando os aprendizes como seres sociais, que se relacionam.

Por fim, chama-se a atenção ao fato de nenhum dos trabalhos analisados abordar a Educação Profissional e Tecnológica, mesmo com a expansão dessa modalidade de ensino na 
última década, requerendo, portanto, um olhar mais atento dos pesquisadores para essa modalidade de ensino.

\section{Referências}

CRUZ, Antônio A.C.; RIBEIRO, Vanessa. G.P..; LONGHINOTTI, Elisane; MAZZETTO, Selma E.. A Ciência Forense no ensino de Química por meio da experimentação investigativa e lúdica. Química Nova na Escola, São Paulo, v. 38, n. 2, p. 167-172, 2016.

De OLIVEIRA, Jane Raquel Silva. Contribuições e abordagens das atividades experimentais no ensino de ciências: Reunindo elementos para a prática docente. Acta Scientiae. Canoas. v. 12, n.1, p.139-153, jan./jun. 2010.

De SOUZA, Fabio Luiz; MARTINS, Patrícia. Ciência e tecnologia na escola: Desenvolvendo cidadania por meio do projeto "Biogás-Energia renovável para o futuro". Química Nova na Escola, v. 33, n. 1, p. 19-24, 2011.

De SOUZA, Paulo Vitor Teodoro; SILVA, Douglas; AMAURO, Quintino; MORI, Rafael Cava; MOREIRA, Patrícia Flavia da Silva Dias. Densidade: uma proposta de aula investigativa. Química Nova na Escola, v. 37, n. 2, p. 120-124, 2015.

ECHEVERRIA, María Del Puy Pérez; POZO, Juan Ignacio. Aprender a Resolver Problemas e Resolver Problemas para Aprender. In: POZO, Juan Ignacio. (Org.). La solución de problemas. Madrid: Santillana, 1994.

FERREIRA, Luiz Henrique; HARTWIG, Dácio Rodney; OLIVEIRA, Ricardo Castro de. Ensino experimental de química: uma abordagem investigativa contextualizada. Química Nova na Escola, v. 32, n. 2, p. 101-106, 2010.

GALIAZZI, Maria do Carmo; GONÇALVES, Fábio Peres. A natureza pedagógica da Experimentação: Uma pesquisa na Licenciatura em Química. Revista Química Nova na escola, v. 27, n. 2, p.326-331, 2004.

GIORDAN, Marcelo. O papel da experimentação no ensino de ciências. Revista Química nova na escola, v.10, n.10, p.43-49, 1999.

GOI, Mara Elisângela Jappe; SANTOS, Flávia Maria Teixeira dos. Reações de Combustão e Impacto Ambiental por meio de Resolução de Problemas e Atividades Experimentais. Revista Química Nova na Escola, v. 31, n.3, 2009.

GUIMARÃES, Cleidson Carneiro. Experimentação no Ensino de Química: Caminhos e Descaminhos Rumo à Aprendizagem Significativa. Revista Química Nova na Escola. V. 31, n.3, p.198, 2009.

HOFSTEIN, Avi; KIPNIS, Mira; ABRAHAMS, lan. How to learn in and from science laboratories. In: EILKS, Ingo; HOFSTEIN, Avi. (Eds.). Teaching chemistry: a study book: A Practical Guide and Textbook for Student Teachers.. Rotterdam: Sense, 2013.

KASSEBOEHMER, Ana Cláudia; FERREIRA, Luiz Henrique. O método investigativo em aulas teóricas de Química: estudo das condições da formação do espírito científico. REEC: Revista electrónica de enseñanza de las ciencias, v. 12, n. 1, p. 144-166, 2013. 
LOPES, J. Bernardino. A Resolução de Problemas em Física e Química: modelo para estratégias de ensino-aprendizagem. Portugal: Texto Editora, 1994.

POZO, Juan Ignacio (org). A Solução de Problemas: Aprender a resolver, resolver para aprender. Porto Alegre: Artmed, 1998.

SCHNETZLER, R.P. Concepções e alertas sobre formação continuada de professores de Química. Química Nova na Escola, n. 16, p. 15-20, 2002.

SILVA, Daniela Rodrigues da; DEL PINO, José Cláudio. Um Estudo do Processo Digestivo como Estratégia para Construção de Conceitos Fundamentais em Ciências. Química Nova na Escola. v. 31, n. 4 , novembro 2009.

SOUZA, Cleuzane R, SILVA. Fernando C.. Uma Sequência Investigativa Relacionada à Discussão do Conceito de Ácido e Base. Química Nova na Escola. v. 40, n. 4 , novembro 2018.

SUART, Rita de Cassia; MARCONDES, Maria Eunice Ribeiro; LAMAS, Maria Fernanda Penteado. A Estratégia "Laboratório Aberto" para a Construção do Conceito de Temperatura de Ebulição e a Manifestação de Habilidades Cognitivas. Revista Química Nova na Escola, v.32, n.3, 2010.

SUART, Rita de Cassia; MARCONDES, Maria Eunice Ribeiro. As habilidades cognitivas manifestadas por alunos do ensino médio de química em uma atividade experimental investigativa. Revista Brasileira de Pesquisa em Educação em Ciências, v.8, n.2, 2008.

VIEIRA, Denise de Oliveira, BRAGA, Marcel Bruno P., PASSOS, Raimundo Ribeiro, FARIAS, Sidilene de Aquino. Estudos sobre o ensino e aprendizagem de conceitos em eletroquímica: uma revisão. Ensino de Ciências e Tecnologia em Revista, v.11, n.1, p. 172-188, 2021.

ZAPPE, Janessa Aline; BRAIBANTE, Mara Elisa Fortes. Contribuições através da temática agrotóxicos para a aprendizagem de química e para a formação do estudante como cidadão. Revista electrónica de enseñanza de las ciencias, v. 14, n. 3, p. 392-414, 2015.

\section{Agradecimentos}

À CAPES pela concessão da bolsa de estudos. 